\title{
Single Source Precursor Growth and Characterization of CdSe Semiconductor Nanomaterial : a Crossing Study between Chemical and Physical Analyses
}

\author{
D. Arl $^{1}$, S. Dalmasso ${ }^{2}$, F. Aubriet ${ }^{1}$, J.-J. Gaumet $^{1}$, J.-P. Laurenti ${ }^{2}$ \\ ${ }^{1}$ Laboratoire de Spectrométrie de Masse et de Chimie Laser \\ ${ }^{2}$ Laboratoire de Physique des Milieux Denses \\ Université Paul Verlaine - Metz, 1 Boulevard Arago, F-57078 Metz Cedex 03 \\ arl@univ-metz.fr
}

\begin{abstract}
II-VI nanoparticles were synthesized by a single source precursor thermal growth which allows control of crystallinity and sized-polydispersion. CdSe nanoparticules were characterized by mass spectrometry and optical spectroscopy (Photoluminescence and absorption) techniques. They present a specific structuration and evidence exciton confinement effects.
\end{abstract}

\section{Introduction}

The study of nanometer-sized crystallites provides a unique opportunity to observe the evolution of material properties with their size. II-VI nanosemiconductors (Nano-SC) is a favourite subject due to the evolution of their electronic properties during the consolidation process of these materials ${ }^{1}$. As an example, in cadmium selenide (CdSe) fundamental excitonic transition evolutes from yellow $(\varnothing$ size $2.5 \mathrm{~nm})$ to red $(\varnothing$ size $6.8 \mathrm{~nm})$ spectral ranges due to quantum confinement effects ${ }^{2,3}$.

However the synthesized nanocrystals (NC) have to present a high crystallinity rate with size and form distributions $<5 \%$. Thus, the recent progress in understanding the physical properties of nanoclusters are linked to an improvement in the methods of preparation of high quality $\mathrm{NCs}^{3}$. One of the main synthesis pathway lays on the single source precursor methodology based on the introduction of a chalcogenide metal cluster in an alkylamine solvent to finally produce cadmium or zinc thiophenolate ${ }^{4}$. Optical spectroscopy techniques of nanodispersions - room temperature photoluminescence (RTPL) and absorption - allow the analysis of these quantum size effects ${ }^{1}$. The confinement of electron-hole pairs in low size crystals enhances significantly transition efficiencies and enables one to operate at room temperature. Mass spectrometry (MS) technique provides additional data about composition, size, surface and stability of nanoparticules ${ }^{5}$. With MS, it is possible to detect pseudomolecular ion with the ratio mass over charge $(\mathrm{m} / \mathrm{z})$ and to get structure data by the so-called MS/MS fragmentation process ${ }^{6}$.

This paper illustrates the unique combination of MS (Laboratory 1) and optical spectroscopy (Laboratory 2) in characterizing nanosemiconductors and their precursors. These two techniques allow the exploration of the size and the composition of these materials.

\section{Experimental}

\section{A/ Elaboration of NCs}

1. Precursor synthesis. The precursor clusters $\left[\left(\mathrm{CH}_{3}\right)_{4} \mathrm{~N}_{2}\left[\mathrm{M}_{4}\left(\mathrm{SC}_{6} \mathrm{H}_{5}\right)_{10}\right]\right.$ and $\left[\left(\mathrm{CH}_{3}\right)_{4} \mathrm{~N}\right]_{4}\left[\mathrm{E}_{4} \mathrm{M}_{10}\left(\mathrm{SC}_{6} \mathrm{H}_{5}\right)_{10}\right](\mathrm{E} \equiv \mathrm{S}$ or $\mathrm{Se}, \mathrm{M} \equiv \mathrm{Cd}$ or $\mathrm{Zn})$ named hereafter " $\mathrm{M}_{4}$ " and " $\mathrm{M}_{10}$ " respectively were prepared by literature methods ${ }^{7,8}$. Figs. 1 and 2 show the general structure of 
the clusters. Note that each capped chalcogenide is bounded with a phenyl group not shown for clarity reason.

2. Thermal growth of CdSe NCs. CdSe NCs were prepared by thermal growing of $\mathrm{Cd}_{10} \mathrm{Se}_{4}$ mixed in hexadecylamine (HDA, m.p.: $47^{\circ} \mathrm{C}$ ). HDA is used both as a solvent and to functionnalize. The chemicals are introduced under argon atmosphere in a three neck round bottom flask heated with an oil bath. The temperature was increased in increments of $2^{\circ} \mathrm{C} \cdot \mathrm{min}^{-1}$. Samples of nanomaterials were taken at fixed temperatures between 180 and $315^{\circ} \mathrm{C}$.

\section{B/ Characterization}

1. Mass spectrometry. MS analyses were performed in the negative ion mode by using a Fourier Transform Ion Cyclotronic Resonance Mass Spectrometer (FTICRMS). This apparatus is an IonSpec HiRes FTICRMS (Varian Corporation, Palo Alto, USA) operating in a $9.4 \mathrm{~T}$ shielded superconducting magnet and coupled to an electrospray source ${ }^{9}$. The ionization process was induced by a spray voltage ranging from -3.8 to $-4.2 \mathrm{kV}$. Sample cone voltage was fixed between -15 and $-130 \mathrm{~V}$.

2. Optical characterization. The NCs are diluted in a toluene bath. For absorption measurements, a white light produced by a Quartz-Iode source illuminates the bath. The transmitted light is dispersed by grating and analysed by CCD camera. For RTPL spectroscopy a He-Cd laser $(325 \mathrm{~nm})$ excites the same bath of NCs. The emitted signal is dispersed and analysed by a similar spectrometric setup.

\section{Results and discussion}

\section{A/ Mass spectrometry.}

Fig. 1 shows a typical mass spectrum when using electrospray source ionization (ESI) coupled to FTICRMS on a metal thiophenolate precursor. Low energy ionization mode allows the observation of a pseudomolecular ion at $\mathrm{m} / \mathrm{z}=771$ which is a double charged species $\left[\mathrm{Cd}_{4}\left(\mathrm{SC}_{6} \mathrm{H}_{5}\right)_{10}\right]^{2-}$ for the $\mathrm{Cd}_{4}$ precursor.

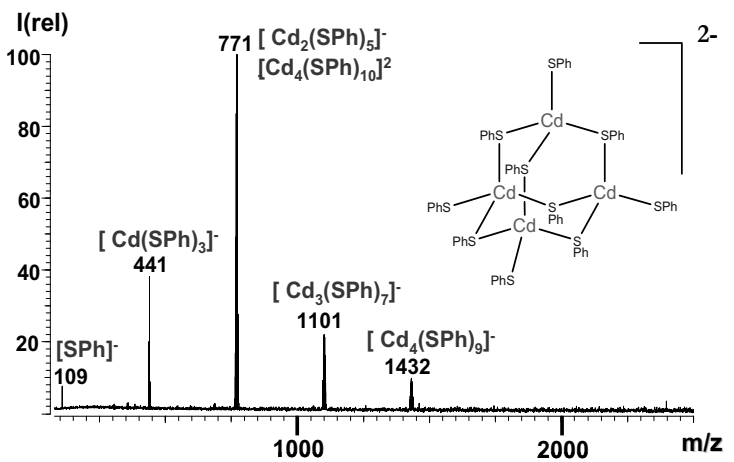

Fig.1. ESI-FTICR Mass spectrum of $\left[\mathrm{Cd}_{4}\left(\mathrm{SC}_{6} \mathrm{H}_{5}\right)_{10}\right]^{-2}$

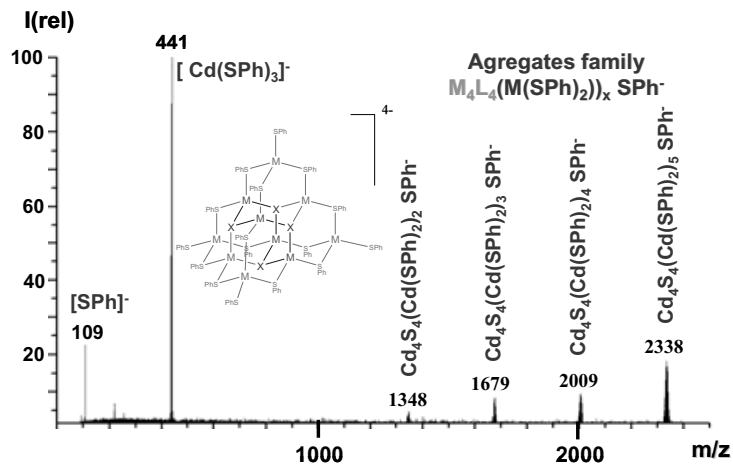

Fig.2. SORI mode fragmentation $\left(\mathrm{N}_{2}\right.$ collision $)$ mass spectrum of $\left[\mathrm{Cd}_{10} \mathrm{~S}_{4}\left(\mathrm{SC}_{6} \mathrm{H}_{5}\right)_{14}\right]^{-2}$

MS technique is a powerful tool as it gains insight into precursor stability. FTICRMS allows high resolution mass spectrometry as we can observe a second distribution at the same $\mathrm{m} / \mathrm{z}$ due to the monocharged species $\left[\mathrm{Cd}_{2}(\mathrm{SPh})_{5}\right]^{-}$. The comparison of the two ions shows an accuracy of $0.5 \mathrm{ppm}$ as the mass difference between $\left[\mathrm{Cd}_{4}\left(\mathrm{SC}_{6} \mathrm{H}_{5}\right)_{10}\right]^{2-}$ and $\left[\mathrm{Cd}_{2}\left(\mathrm{SC}_{6} \mathrm{H}_{5}\right)_{5}\right]^{-}$in 770.8637 and 770.8633 respectively. Note the resolution value is $\mathrm{m} / \Delta \mathrm{m}=1.92 \times 10^{6}$. 
When using fragmentation process in a mass spectrometer, it is possible to get structural informations. Fig. 2 shows the mass spectrum resulting from an MS/MS experiment of the cluster " $\mathrm{Cd}_{10}$ ". The fragmentation technique applied herein was the Sustained Off resonance Irradiation-Collision Induced Dissociation (SORI-CID) method with the following parameters : source temperature $=100^{\circ} \mathrm{C}$, excitation amplitude $=9 \mathrm{~V}$, collision gas $\left(\mathrm{N}_{2}\right)$ pulse duration $=10 \mathrm{~ms}$. We observe in fig. 2 the build-up of an ion cluster family with the general formular $\left[\mathrm{Cd}_{4} \mathrm{Se}_{4}\left(\mathrm{Cd}\left(\mathrm{SC}_{6} \mathrm{H}_{5}\right)_{2}\right)_{\mathrm{n}}\left(\mathrm{SC}_{6} \mathrm{H}_{5}\right)\right]^{-}$with $0 \leq \mathrm{n} \leq 6 . \mathrm{SC}_{6} \mathrm{H}_{5}{ }^{-}$and $\mathrm{Cd}\left(\mathrm{SC}_{6} \mathrm{H}_{5}\right)_{3}{ }^{-}$at $\mathrm{m} / \mathrm{z}=109$ and 441 respectively are always abundant as they are coming from the loss of the capping part of the ion clusters with or without MS/MS. However we do not observed $\mathrm{Cd}_{2}\left(\mathrm{SC}_{6} \mathrm{H}_{5}\right)_{5}{ }^{-}, \mathrm{Cd}_{3}\left(\mathrm{SC}_{6} \mathrm{H}_{5}\right)_{7}{ }^{-}$and $\mathrm{Cd}_{4}\left(\mathrm{SC}_{6} \mathrm{H}_{5}\right)_{9}{ }^{-}$which proves the remarkable stability of the cluster core in fig.2. Note that the mass spectra are similar when using $\mathrm{Zn}$ and $\mathrm{S}$ in precursor combinations. This shows that a neutral species $\mathrm{M}_{4} \mathrm{E}_{4}$ (with $\mathrm{M} \equiv \mathrm{Zn}$ or $\mathrm{Cd}$ and $\mathrm{E} \equiv \mathrm{S}$ or $\mathrm{Se}$ ) is a very stable particle and we are currently exploring different fragmentation techniques coupled to the FTICRMS for a better knowledge of the structure of this cluster.

At the moment, these results concern precursors only; further works on thermally grown NCs are in progress.

\section{B/ Optical spectrometry.}

Figs.3 shows some typical absorption (a) and RTPL (b) spectra obtained from thermally grown CdSe NCs diluted in a toluene bath. The general features compare with previous
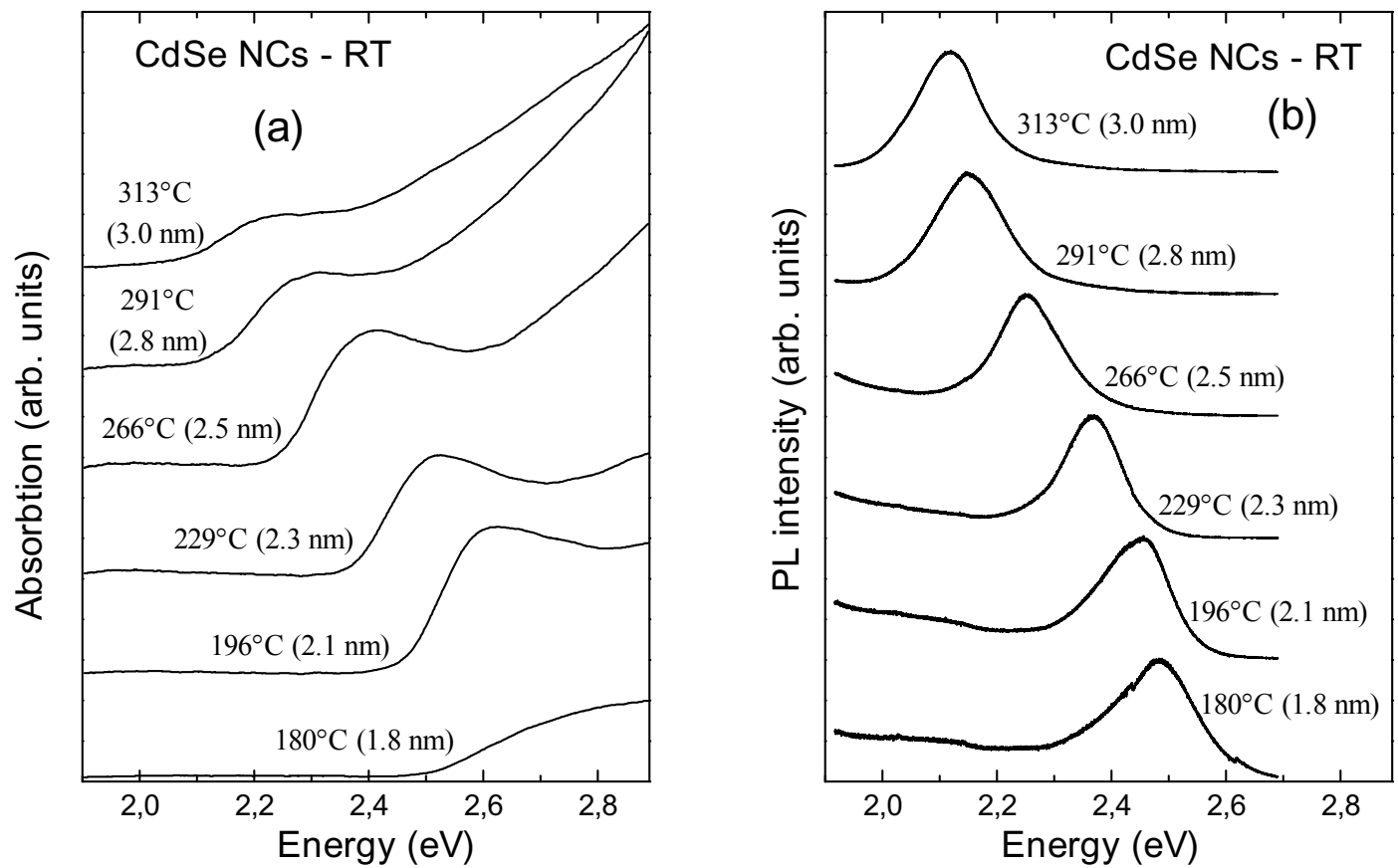

Fig.3. RT absorption (a) and PL (b) spectra of CdSe NCs diluted in a toluene bath for various growth temperatures indicated near every spectrum. The average diameters of the NCs, tentatively estimated after energy-size empirical correspondence, are displayed within brakets.

results in the field of high quality $\mathrm{NCs}^{10}$. In particular, (i) the fundamental excitonic transition merges from most of the absorption spectra as a band characteristic of quantum confinement ; however, probably due to residual size dispersion, the transitions involving higher confinement levels are not resolved; (ii) the RTPL spectra are dominated by a strong 
recombination band close to the fundamental absorption edge which indicates an excitonic character of the observed transition, although a trend toward a very broad band (not investigated here) is observed at low energy; (iii) in both series of spectra, the quantum size effect is evidenced by a downshift of the transition energies when the growth temperature increases ; using commonly admitted energy-size empirical correspondence ${ }^{11}$, the average diameters of the NCs is tentatively estimated (displayed within brakets in fig.3) and ranges between 1.8 and $3.0 \mathrm{~nm}$.

\section{Conclusion}

CdSe NCs were synthesized by a single source precursor thermal growth. They were characterized as well as their precursors by the unique combination of MS and optical spectroscopy. These two techniques allow the exploration of the size and the composition of these materials. Mass spectrometry provides specific fingerprints for each precursor of NCs. Furthermore, this technique helps to get some data concerning the stability of some clusters or fragments that may help to understand the growth of these precursors and the final NCs. Absorption and RTPL spectrometries performed on the NCs diluted in toluene clearly evidenced exciton confinement effects. However, some residual size dispersion is suggested by the shape of the absorption spectra in the high energy side. Further MS results on thermally grown NCs will be helpful to clarify this question and optimally improve the growth protocol.

\section{Acknowledgments.}

The authors acknowledge financial support from the French Minister of Education and Research.

1. S.L. Cumberland, K.H. Hanif, A. Javier, G.A. Khitrov, G.F. Strouse, S.M. Woessner and C.S. Yun, Inorganic Clusters as Single-Source Precursors for Preparation of CdSe, ZnSe and CdSe/ZnS Nanomaterials. Chem. Mater. 14(4), 1576 (2002).

2. P. Reiss, S. Carayon, J. Bleuse and A. Pron, Low Polydispersity Core/shell Nanocrystals of CdSe/ZnSe and CdSe/ZnSe/ZnS Type: Preparation and Optical Studies. Synth. Met. 139, 649 (2003).

3. P. Reiss, S. Carayon and J. Bleuse, Large Fluorescence Quantum Yield and Low Size Dispersion from CdSe/ZnSe Core/shell Nanocrystals. Physica E17, 95 (2003).

4. M. Green and P. O'Brien, Recent Advances in the Preparation of Semiconductors as Isolated Nanometric Particles: New Routes to Quantum Dots. Chem. Commun.,22, 2235 (1999).

5. J.J. Gaumet, G.A. Khitrov and G.F. Strouse, Mass Spectrometry Analysis of the $1.5 \mathrm{~nm}$ Sphalerite-CdS Core of $\left[\mathrm{Cd}_{32} \mathrm{~S}_{14}\left(\mathrm{SC}_{6} \mathrm{H}_{5}\right)_{36} ; D M F_{4}\right]$. Nano Lett. 2, 375 (2002).

6. V. Gabelica and E. De Pauw, Internal energy and fragmentation of ions produced in electrospray sources. Mass Spectrometry Reviews, 24, 566 (2005).

7. I.G. Dance, A. Choy and M.L. Scudder, Syntheses, Properties, and Molecular and Crystal Structures of $\left(\mathrm{Me}_{4} \mathrm{~N}\right)_{4}\left[\mathrm{E}_{4} \mathrm{M}_{10}(\mathrm{SPh})_{16}\right]$ Molecular Supertetrahedral Fragments of the Cubic Metal Chalcogenide Lattice. J. Am. Chem. Soc. 106, 6285 (1984).

8. C.B. Murray, D.J. Norris and M.G. Bawendi, Synthesis and Characterization of Nearly Monodisperse $C d E(E=S, S e, T e)$ Semiconductor Nanocrystallites. J.Am.Chem.Soc., 115, 8706 (1993).

9. Manisali, I.C., Chen, D.D.Y, Schneider, B., Electrospray ionization source geometry for mass spectrometry: past, present and future. Trends in analytical chemistry, 25, 243 (2006).

10. J.A. Gerbec, D. Magana, A. Washington and G.F. Strouse, Microwave-Enhanced Reaction Rates for Nanoparticule Synthesis. J. Am. Chem. Soc. 127, 15791 (2005).

11. W. YU, L. Qu, W. Guo and X. Peng, Experimental Determination of the Extinction Coefficient of CdTe, CdSe and CdS Nanocrystals. Chem. Mater. 15, 2854 (2003). 